based on only six patients have doubtful statistical significance and clinical relevance.

Thus it is not surprising that the conclusions drawn by the authors are not supported in the existing literature. Indeed, there is a large body of data now available attesting to the long term safety of sphincterotomy in patients with intact gall bladders. ${ }^{3}$ Furthermore, there is considerable evidence that sphincterotomy may enhance gall stone clearance from the gall bladder in animals and man. For example, dynamic scintigraphic studies using cholecystokinin in dogs have shown increased ejection fractions after sphincterotomy. Safe and effective use of endoscopic sphincterotomy of the gall bladder in a wider population can be supported only by correctly designed controlled clinical trials.

RICHARD HORTON ADRIANO LAURI

Hepatobiliary and Liver Transplantation Unit,

Royal Free Hospital and School of Medicine,

London NW3 2QG

1 Desa LA, Grace PA, Vipond MN, Henderson B, Thompson JN Gall bladder function after endoscopic sphincterotomy. Gall bladder function after en

2 Sherlock S. Diseases of the liver and biliary system. 8th ed. Oxford: Blackwell Scientific Publications, 1989:624-5.

3 Jacobsen IM. Endoscopic sphincterotomy in patients with intac gall bladders. In: Jacobson IM, ed. ERCP: diagnostic and therapeutic applications. New York: Elsevier, 1989:127-9.

4 Hutton SW, Sievert CE, Vennes JA, Shafer RB, Duane WC Spontaneous passage of glass beads from the canine gall bladder: facilitation by sphincterotomy. Gastroenterolog 1988; $94: 1031-5$

SIR,-Mr L A Desa and colleagues report non-functioning of the gall bladder after sphincterotomy, but we wish to make the following comments with respect to their conclusions.'

Firstly, entry of contrast material into the gall bladder at endoscopic retrograde cholangiopancreatography demonstrates only patency of the cystic duct and does not represent intact gall bladder function. Secondly, failure of gall bladder filling in patients with previous sphincterotomy does not necessarily indicate gall bladder dysfunction. Indeed, this would be an expected finding, because the radiolabelled bile would freely flow through the dilated sphincter of Oddi.

In healthy subjects the mean peak pressure at the sphincter of Oddi during phasic contractions is $100 \mathrm{~mm} \mathrm{Hg}$ greater than the intraduodena pressure $^{2}$ and holds back bile so that it enters the gall bladder. This pressure is also similar in patients with common bile duct stones or gall stones. During the open relaxation phase the sphincter pressure decreases to about $15 \mathrm{~mm} \mathrm{Hg}$ higher than the intraduodenal pressure. ${ }^{3}$ In man the sphincter of Oddi functions as a variable resistor-variation in its tone routes hepatic bile into the duodenum or towards the gall bladder. ${ }^{4}$

In subjects with previous sphincterotomy, in whom this sphincter pressure is abolished, it would be natural for the bile to take the path of least resistance and drain freely into the duodenum without entering the gall bladder. This cannot be taken as evidence of a non-functioning gall bladder The authors assume that the only stimulus to gal bladder contraction is distension by filling of bile. The implication that sphincterotomy would lead to failure of gall bladder contraction, with retention of stones and stasis of bile with consequent sepsis and carcinoma, is questionable.

J D ARNOLD

W E WILKIN

Department of Medicine,

Princess of Wales Hospital,

Bridgend,

Mid Glamorgan CF31 1JP

B W LAWRIE

University Hospital of Wales,

Cardiff CF4 4XW

1 Desa LA, Grace PA, Vipond MN, Henderson B, Thompson JN Gall bladder function after sphincterotomy. $B r$ Med $f$ 1990;300:1111. (28 April.)
Csendes A, Kruse A, Funch-Jensen P, et al. Pressure measurements in the biliary and pancreatic duct systems in controls and in patients with gallstones, previous cholecystectomy, or

3 Meshikinpour H, Mollot M, Eckerling GB, Bookman Bile duct dyskinesia: clinical and manometric study. Gastroenterology 1984;87:759-62.

4 Dodds WJ, Hogan WJ, Grenen JE. Perspectives about functio of the sphincter of Oddi. Viewpoints on Digestive Diseases 1989;20:9-12.

AUTHORS' REPLY, - We cannot agree with any of the criticisms of our study made by Drs Horton and Lauri.

Technetium-99m HIDA scanning is a functional test of hepatic uptake and excretion. It may be used to assess biliary system patency, but non-filling of the gall bladder or any other part of the biliary system does not necessarily imply mechanical obstruction. Indeed, non-filling of the gall bladder is seen in a number of conditions despite a patent cystic duct. The response of the gall bladder to exogenous cholecystokinin cannot be regarded as a true test of physiological function.

The reference quoted by Drs Horton and Laur about delayed filling of normal gall bladders was thrice removed from any data (two textbooks and one letter leading to an abstract $\left.{ }^{1}\right)$. This refers to patients with suspected acute cholecystitis, no "normal" gall bladders, and shows that in 17 of 296 patients $(6 \%)$ the gall bladder did not fill at one hour but did so later at one to four hours after injection of radioisotope. Three patients had acute and 14 chronic cholecystitis. As discussed in our report there is a low incidence (about $10 \%$ ) of non-filling of the gall bladder on HIDA scanning in asymptomatic patients with stones, but the chances of this occurring in six consecutive patients are remote (approximately one in $10^{6}$ ).

Presphincterotomy HIDA scans would have been difficult to interpret because most of our patients were jaundiced, and thus had impaired isotope excretion, and had common bile duct stones obstructing the biliary system. The absence of "controls" does not invalidate our observation.

We cannot agree that an observation based on "only six" patients is of doubtful clinical relevance. Indeed, an observation on a single patient may be of great clinical relevance. None the less, we have extended our series to 10 patients (four with scanning up to four hours) and none has shown gal bladder filling. Our finding is also supported by recent necropsy study. ${ }^{2}$ We have no doubt about the validity of our observation.

While we do not doubt the good short term results of sphincterotomy for ductal stones, the safety of sphincterotomy in the long term (more than 10 years) in such patients is not known. Our study suggests caution before extending such a policy to younger patients, who may be expected to live up to 30 or 40 years after operation. Controlled trials have little value in this respect.

Drs Horton and Lauri comment that considerable evidence exists in animals and man showing that sphincterotomy may enhance gall stone clearance from the gall bladder but support this only with a reference to cholecystokinin-induced gall bladder ejection fractions and the passage of glass beads after sphincterotomy in dogs. ${ }^{3}$ The same study showed significantly lowered resting gall bladder volumes after sphincterotomy, which would be consistent with reduced gall bladder filling. The authors of this study were more cautious than Drs Horton and Lauri and concluded, "these preliminary results in an animal model should not be assumed to apply to humans and should not alter our clinical approach to gall stone disease."

Our study has clearly shown the absence of gall bladder filling on HIDA scanning in patients after endoscopic sphincterotomy. We believe that this observation may have important implications and that it certainly warrants further study.

We generally agree with the comments made by

Dr Arnold and colleagues, although we find it difficult to understand how a gall bladder that does not fill with bile can be considered to function normally. While we agree that gall bladder filling is not the only stimulus to gall bladder contraction, a non-distended gall bladder will obviously have less scope for contraction than a distended one. The finding of our study may be expected, but it has not to our knowledge been documented before and it is certainly not widely appreciated.

L A DESA P A GRACE JN THOMPSON

Departments of Surgery and Diagnostic Radiology,

Royal Postgraduate Medical School,

Hammersmith Hospital,

London W12 0NN

Academic Surgical Unit,

St Mary's Hospital,

London W2

I Weissman HS, Sugarman LA, Badia JD, Freeman LM Improving the specificity and accuracy of Tc-99m-IDA cholesyntigraphy with delayed views. I Nucl Med 1980;21:16. 2 Teilum D, Ravnborg L. Sphincter of Oddi and filling of the gallbladder. A necropsy study. Endoscopy 1989;21:131-2.

3 Hutton SW, Sievert CE, Vennes JA, Shafer RB, Duane WC. Spontaneous passage of glass beads from the canine gall bladder: facilitation by sphincterotomy. (iastroenterolog 1988;94:1031-5

\section{Screening for carcinoma of the prostate}

SIR,-Dr Knud V Pedersen and colleagues are enthusiastic about digital rectal examination but doubt whether such screening for early curable cancer of the prostate will lead to prolonged survival. ' This is yet another study on screening for cancer of the prostate that lacks a control group and is, therefore, vulnerable to two fundamental errors. $^{23}$

Firstly, length time bias could occur by concluding that screening is beneficial because asymptomatic tumours diagnosed by screening may have been growing slowly for a long time. The second error, lead time bias, could occur when a tumour is detected early but the natural course of the disease and final outcome are not altered.

Digital rectal examination in non-randomly selected populations has been shown to be an insensitive device with poor predictive values of $26 \%$ and $22 \% .^{45}$ In a similar study offering a free screening service that was publicised through local media and posters but no direct invitations digital rectal examination had a positive predictive value of only $29 \%$ and the important point was made that clinical staging understages the disease and pathological staging can upstage the tumour in a third of patients.

Dr Pedersen and colleagues found 11 of 13 tumours to be "early"- of these patients, 10 underwent radical prostatectomy and one radiotherapy. The authors do not state how many of these patients underwent staging lymphadenectomy or whether on pathological staging there was evidence of lymph node disease or capsular invasion.

Although digital rectal examination may be sound medical practice and both cost effective and practical to set up in primary health centres, there is little evidence that it can achieve its target of reducing the morbidity and mortality from cancer of the prostate. The high prevalence of cancer of the prostate and its variable natural course require a prospective randomised controlled clinical trial to assess properly the value of mass screening.

Transrectal ultrasound scanning studied in an uncontrolled trial was twice as sensitive as digital rectal examination. ${ }^{7}$ It would be unethical to deny patients in the control group digital rectal examination, and therefore it would be reasonable to compare such examination alone and combined with transrectal ultrasound scanning. To prove that screening as proposed by Dr Pedersen and 
colleagues is beneficial a study will have to show that it reduces the mortality from cancer of the prostate. Such a screening programme will require a large population of patients and a minimum of 15 years' follow up.

D P S SANDHU C P CHILTON K W MUNSON

Derbyshire Royal Intirmary Derby DEl 2QY

1 Pedersen KV, Carlsson P, Varenhorst E, Lofman O, Berglund K. Screening for carcinuma of the prostate by digital rectal examination in a randomly selected population. Br Med $\mathcal{F}$ 1990;300:1041-4. (21 April.)

2 Love RR, Camilli AE. The value of screening. Cancer 1981;48 489-95.

3 Chodak GW. Early detection of prostate cancer. Horm Res 1989:32 (suppl 1):35-7

4 Thompson IM, Ernst JJ, Gangai MP, Spence CR. Adenocarcinoma of the prostate: results of routine urological screening. $\mathcal{F}$ Crol 1984;132:690-2.

5 Vihko $P$, Konturri $M$, Lukkarinen $O$, Ervasti J, Vihko $R$. Screening for carcinoma of the prostate. Cancer 1985;56:173-7. 6 Chodak GW, Schoenberg HW. Early detection of prostate cancer by routine screening. JAMA 1984;252:3261-4.

7 Lee F, Littrup PJ, Torp-Pedersen ST, et al. Prostate cancer comparison of transrectal ultrasound and digital rectal examination for screening. Radiology 1988;168:389-94.

Authors' REPLY,-We agree that there is no evidence from randomised studies that screening and potentially curative treatment reduce the overall mortality from carcinoma of the prostate and we agree that length and lead time biases must be considered in judging screening programmes. Contrary to other studies, our population of 1494 men was randomly selected from a total population of 9026 , so that the remaining 8432 who were not examined served as a control group. The follow up time, however, is still too short to enable any conclusions to be drawn.

Concerning the screening method and role of transrectal ultrasound screening, we found that the positive predictive value of digital rectal examination when performed by a urologist was 0.35 , which is similar to the best results of transrectal ultrasound scanning reported.

Staging lymphadenectomy was done in all patients who received potentially curative treatment (10 had radical prostatectomy and one had radiotherapy). One had minimal lymph node disease. Capsular invasion was found in seven cases after radical prostatectomy. These men received postoperative radiotherapy, although its value and the clinical significance of such invasion are not known.

In view of the final staging of the tumours it is most likely that we found and treated clinically significant carcinomas.

ERERHARD VARENHORST

Department of Urology

Norrköping, Sweden

KNUD V PEDERSEN

Department of Urology

University Hospital

Linköping, Sweden

SIR, - The recent paper by Dr Knud V Pedersen and colleagues described the assessment of cost and feasibility of screening for prostatic carcinoma, but their method of screening and their biopsy technique are baffling.

The authors do not say whether the cytologist who took biopsies of apparently abnormal prostates was aware of the clinical findings-this seems improbable because he took three fine needle aspirates from each lobe. If the cytologist was unaware of the site of the nodular areas several of the cancers might have been missed by not biopsying the nodular areas directly. This may explain the relatively low finding of a $30 \%(13 / 44)$ incidence of carcinoma when previous studies have shown an incidence of $50-75 \%$ of carcinoma in prostatic nodules. ${ }^{2}$ It is not stated which of the six biopsies taken in each patient were positive in the patients with carcinoma. Given these circumstances, I do not think that the technique is truly a screening test when such a potential for false negative results exists and the conclusions are thus flawed.

Random biopsying of the prostate gland under other circumstances is known to have a low yield. ${ }^{3}$ It is not surprising to find a $30 \%$ incidence of carcinoma in what is, after all, a highly selected group (men with nodular prostates on rectal examination). From necropsies and simple prostatectomy specimens figures of $5-40 \%$ have been suggested.

Finally, it is gratifying that there was a $100 \%$ response to the questionnaire sent to the men by the authors (though 331 did decline rectal examination for various reasons). This is unique in my experience and very impressive.

PETER A MCCARTHY

Department of Radiology, Hospital of the University of

Pennsylvania, Philadelphia, PA

1 Pedersen $\mathrm{K}$, Carlsson P, Varenhorst E, Löfman O, Berglund $\mathrm{K}$. Screening for carcinoma of the prostate by digital rectal examination in a randomly selected population. Br Med $\mathcal{J}$ 1990;300:1041-4. (21 April.)

2 Grayhack J, Bockrath J. Diagnosis of carcinoma of the prostate. Urology 1981;17(suppl):54

3 Catalona W. Yield from routine prostatic needle hiopsy in patients more than 50 years old referred for urologic evaluation: a preliminary report. $\mathcal{F}$ Urol $1980 ; 124: 844$

4 Catalona W, Scott W. Carcinoma of the Prostate. In: Walsh P. Gittes R, Perlmutter A, Stamey T, eds. Camphell's Urology. Philadelphia: W B Saunders, 1986:1463.

\section{Varicose veins}

SIR,-Mrs Linda de Cossart and Mr R S Kiff report anxiety concerning the safety of bilateral surgery for varicose veins and ask whether a policy of offering to operate on only one leg at a time is out of line with that of other surgeons.

I support that policy wholeheartedly and report that in my practice, owing to pressure on beds, I have not been able to perform bilateral varicose vein surgery for the past five years. Day patients have been offered unilateral flush saphenofemoral ligation and multiple avulsions under general anaesthesia with the option of having surgery for the other leg three months later. Patients are given a single dose of subcutaneous heparin 5000 units with premedication and on discharge are given elastic stockings to wear for three weeks. In our district there will always be another patient with a more pressing claim to an overnight stay in a surgical bed. A realistic appraisal of waiting time for routine surgery on varicose veins would have to be that it is infinite.

To date all my patients have accepted this policy without rancour. In over 300 cases over the past five years only one patient has had a pulmonary embolus. This patient was admitted to a private hospital, where he was given subcutaneous heparin 5000 units two hours preoperatively and twice a day for two days postoperatively and elastic stockings. Despite these measures the patient developed severe pleuritic chest pain after three weeks while on holiday abroad. On returning home he was admitted to hospital and given heparin, and a ventilation-perfusion scan confirmed the diagnosis of pulmonary embolus. The patient made a satisfactory recovery on anticoagulants.

A long term study is now needed to determine whether bilateral surgery is more dangerous than unilateral surgery, and another to show whether the addition of stripping the long saphenous vein from groin to knee, which sometimes precludes day case treatment, is of benefit.

P G BENTLEY

Kent and Sussex Hospital,

Tunbridge Wells,

Kent TN4 8AT

1 de Cossart L, Kiff RS. Varicose veins. Br Med J 1990;300:1273 (12 May.)

\section{Proliferative retinopathy with growth hormone deficiency and diabetes mellitus}

SIR,-Dr C H Thivolet and colleagues report an unusual case of proliferative retinopathy in a woman with growth hormone deficiency and insulin dependent diabetes mellitus.' Both hypertension and renal impairment are known to exacerbate pre-existing diabetic retinopathy but measurements of the patient's blood pressure and renal function are not described.

Insulin like growth factor $I$ is suggested to be a local mediator of diabetic retinopathy. But the authors do not take into account that only a small free fraction of the factor is present in the circulation and that most is bound to carrier proteins. When variations in glycaemic control, duration of diabetes, and renal function are controlled for the total concentrations of circulating insulin like growth factor I are relatively low in patients with advanced retinopathy. ${ }^{2}$ Local tissue concentrations of free insulin like growth factor I and its binding proteins are probably more relevant, and recently the $40 \mathrm{kDa}$ complex of the factor and small binding protein has been found in the vitreous of patients with proliferative diabetic retinopathy. ${ }^{3}$ Further studies are required to elucidate the role of insulin like growth factor I and its binding proteins in the development of diabetic retinopathy.

The authors also state that hyperinsulinism may explain the observed normal concentrations of insulin like growth factor $I$ in the patient and that insulin may be critical in the control of the secretion of the factor. Unfortunately, no measurements of insulin or $\mathrm{C}$ peptide secretion are detailed to support this contention. This explanation is probably oversimplified because evidence is growing of an inverse relation between concentrations of insulin and one of the small binding proteins known as insulin like growth factor binding protein $\mathrm{I}^{+}$Understanding of the effect insulin like growth factor I and its binding proteins have on glucose homeostasis is still incomplete.

J D QUIN

A C MACCUISH

Diabetic Unit,

Glasgow Royal Infirmary,

Glasgow G4 0SF

Gartnavel General Hospital,

Glasgow G12 0YN

1 Thivolet $\mathrm{CH}$, Mirakian P, Chatelain P, Fournier P, Tournaire J. Proliferative retinopathy in a woman with growth hormon deficiency and diabetes mellitus. Br Med $\mathcal{Y}$ 1990;300:979-80. (14 April.)

2 Arner P, Sjorberg S, Gjottersbeg M, Skottner A. Circulating insulin like growth factor $I$ in type I (insulin-dependent) diabetic patients with retinopathy. Diabetologia 1989;32 753-8

3 Grant M, Russell B, Fitzgerald C, Merimee TJ. Insulin like growth factors in vitreous: studies in control and diabetic
subjects with neovascularization. Diabetes 1986;35:416-20.

4 Holly JMP, Biddlecombe RA, Dunger DB, et al. Circadian variation of growth hormone independent insulin like growth factor binding protein in diabetes mellitus and its relationship to insulin. A new role for insulin? Clin Endocrinol ship to insulin.

AUTHOR'S REPLY,-The suggested relation between blood pressure and renal impairment and proliferative retinopathy in our patient was unlikely to be important because proteinuria and hypertension occurred later.

Total concentrations of circulating insulin like growth factor $I$ in proliferative retinopathy may be either increased or normal in adult patients. The study by Arner et al, showing low insulin like growth factor I concentrations, is unique and should be reproduced by others. We agree that the complex of $40 \mathrm{kd}$ and insulin like growth factor I may be particularly important and we will measure 